\title{
Commentary
}

\section{Role of the $\beta_{3}$ Integrin Subunit in Human Primary Melanoma Progression}

\section{Multifunctional Activities Associated with $\alpha_{v} \beta_{3}$ Integrin Expression}

\author{
Richard E. B. Seftor \\ From the Department of Anatomy and Cell Biology, University of \\ Iowa, Iowa City, Iowa
}

Recent research into how cells interact with and function within their different (and sometimes dynamically changing) environments has become a primary focus of cell biology, centering on the examination of cell surface adhesion receptors, most notably the integrins..$^{1,2}$ Integrins form one family of cell adhesion receptors, which also include the immunoglobulin gene superfamily, selectins, cadherins, cartilage-link proteins, and cell mucins (which act as ligands for the selectins). All integrins are heterodimers composed of noncovalently linked $\alpha$ and $\beta$ subunit transmembrane glycoproteins containing large extracellular domains, short transmembrane domains, and carboxy-terminal cytoplasmic domains of variable length. ${ }^{1-5}$ There are presently $17 \alpha$ subunits and eight $\beta$ subunits known, which occur in just over 20 integrins identified so far. However, these numbers may belie the added complexity introduced by the alternately spliced cytoplasmic domains observed in some variants of these subunits. ${ }^{1,6}$ The eight $\beta$ subunits share approximately 40 to $80 \%$ amino acid sequence homology and are similar in size (90 to $110 \mathrm{kd}$ ) except for the $\beta_{4}$ chain, which is almost twice as big because of its large intracytoplasmic domain. The $\beta$ chains contain a fourfold repeat of cysteinrich segments and a highly conserved cytoplasmic domain with an Asp-X-Ser-X-Ser sequence (where $X$ is any amino acid) associated with cation-dependent ligand binding and with the metal ion-dependent adhesion site motif. 2,7 This cytoplasmic tail region of the $\beta$ subunits has been implicated both in cytoskeletal interactions and with signaling complexes. The $\alpha$ subunits, with molecular weights ranging between 120 and $180 \mathrm{kd}$, tend to be more heterogeneous than the $\beta$ subunits. Furthermore, some $\alpha$ units contain light and heavy chains linked by a disulfide bridge in the extracellular domain, whereas other $\alpha$ subunits contain an extra segment of approximately 180 amino acids called the $\alpha \mathrm{A}$-domain ${ }^{7}$ (or I domain $)^{1,2}$ inserted before the last five homologous repeats, which contain a cation-binding domain. This $\alpha$ A-domain contains a sequence homologous to the collagen-binding domains of von Willebrand factor, cartilage matrix protein, and complement proteins. Only recently has functional activity in recombinant versions of this domain permitted the opportunity to study ligand binding; the fragment $\alpha \mathrm{L}$ A-domain has been shown to bind the intercellular cell adhesion molecule-2 (ICAM-2) and the fragment $\alpha 1 / \alpha 2$ A-domain has been shown to bind to laminins. ${ }^{7}$ All $\alpha$ subunits contain a sevenfold repeat of a homologous segment with the last three or four repeats containing the sequence Asp-X-Asp-X-Asp-Gly-X-X-Asp ${ }^{1}$ (or related sequence) $)^{2}$ motif. This motif is associated with the divalent cation-binding EF-handlike domains ${ }^{2,7}$ and contributes to cation-dependent ligand binding to the integrin receptor. While divalent cations are required for receptor function they can also, depending on the nature of the cation, affect both the integrin's affinity and specificity for ligands. ${ }^{1-5,7}$ Some integrins also require divalent cations for their $\alpha \beta$ subunit association. ${ }^{1,8,9}$ In general, whereas the theoretical number of integrin heterodimers exceeds 100, the 20-plus observed integrins fall into three basic groups based on similar chain structures and/or the ability to recognize similar protein or adhesion motifs. These three groups include integrins which contain the $\beta_{1}, \beta_{2}$, and $\beta_{3}$ or $\alpha_{v}$ subunits; three $\alpha \beta$ integrins do not fall within these groups. ${ }^{1,2}$ Many $\alpha$ subunits can associate with just one of the $\beta$ subunits, although some

Accepted for publication September 3, 1998

Address reprint requests to Dr. Richard E.B. Seftor, Department of Anatomy and Cell Biology, University of lowa, 51 Newton Road, 1-100L BSB, lowa City, IA 52242-1109. E-mail: richard-seftor@uiowa.edu. 
$\alpha$ subunits can associate with more than one $\beta$ subunit. In particular, the $\alpha_{v}$ subunit appears to be one of the most promiscuous of the $\alpha$ subunits and can associate with at least five different $\beta$ subunits, including the $\beta_{1}$ chain (see below). Although originally identified as cell adhesion molecules (both cell-extracellular matrix and cell-cell), integrins have most recently been shown to play significant roles in signal transduction events, ${ }^{1-7,10-27}$ gene expression, ${ }^{12,25,28}$ cell proliferation, ${ }^{12,13,15,17,26,27,29}$ regulation of apoptosis $^{30-33}$ and anoikis, ${ }^{32}$ invasion and metastasis, ${ }^{2,10-}$ $12,21,26,29,33-37$ embryogenesis, ${ }^{38-41}$ tumor progression, ${ }^{29}$ inflammation and immunity, ${ }^{28}$ hemostasis, ${ }^{42}$ and angiogenesis. ${ }^{26,33,43-48}$ Recent studies have also identified integrins as points of entry for certain infection agents including hantaviruses, which appear to use the $\beta_{3}$-containing integrins to gain entry into cells, ${ }^{49}$ and Lyme disease spirochetes, whose attachment to human cells is mediated by the $\alpha_{\mathrm{v}} \beta_{3}$ and $\alpha_{5} \beta_{1}$ integrins. $^{50}$

Integrin function in normal and pathological processes in terms of ligand and adhesive specificity was initially determined using cell adhesion assays, monoclonal antibodies, and affinity chromatography. ${ }^{1,2}$ It became apparent that individual integrins can often bind to different ligands and that different ligands are recognized by more than one integrin. Integrins bind to extracellular matrix proteins and facilitate cell-substratum adhesion and, in the case of the ligand fibrinogen, can facilitate cell-cell aggregation. Some integrins can also recognize integral membrane proteins of the immunoglobulin superfamily (ICAM-1, ICAM-2, and VCAM-1) and thereby mediate direct cell-cell adhesion (ie, recognize and bind to a counterreceptor on other cells). The first defined integrin recognition site was the sequence Arg-Gly-Asp (RGD), ${ }^{1-5}$ found in fibronectin, vitronectin, and other adhesive proteins. Subsequent binding motifs identified include Lys-GIn-Ala-Gly-Asp-Val (KQAGDV) in fibrinogen, Asp-Gly-Glu-Ala (DGEA) in type I collagen, Glu-lle-LeuAsp-Val (EILDV) in an alternatively spliced segment of fibronectin, and Gly-Pro-Arg-Pro (GPRP) in fibrinogen. Whereas the integrins that bind laminin appear to recognize specific parts of the laminin molecule, integrins that bind counterreceptors appear to recognize specific immunoglobulin-like domains. ${ }^{1,2}$

At present, integrins are described structurally as heterodimeric glycoproteins that contain an extracellular ligand-binding site composed of the $N$-terminal domains of the $\alpha$ and $\beta$ subunits. This region is connected by two stalks, one from each subunit, to the membrane-spanning segments and ends at the $\alpha$ and $\beta$ subunit cytoplasmic domains. All current evidence indicates that these cytoplasmic domains interact with cytoskeletal proteins and components. The cytoplasmic tail of some $\beta$ subunits appears to direct integrin receptors in a ligand-independent manner to focal adhesion sites where the integrins become organized at the ends of actin filaments. These focal contacts also contain the proteins vinculin, talin, and $\alpha$-actinin, which are thought to mediate interactions between the ligand-integrin structure outside the cell and the actin microfilaments inside the cell. ${ }^{1,2,7}$ The cytoplasmic tail of some $\alpha$ subunits appear to convey ligandspecific signals to the cells in response to the integrin binding its ligand. ${ }^{51}$ In contrast, the $\alpha_{6} \beta_{4}$ integrin is unique in that it becomes concentrated in epithelial cells specifically at hemidesmosomes and is thought to interact with the intermediate filaments characteristic of hemidesmosome structure. ${ }^{1}$

We now know that individual cells can vary their adhesive properties by selectively expressing different integrins and by modulating their integrin specificity and affinity for ligands through a process known as integrin activation and deactivation. The change in integrins' activation/deactivation state as a conformation change in the receptors' extracellular domains has been detected using both immunohistochemical and biophysical techniques and could relate to the degree of phosphorylation of the $\beta$ subunit (see below) ${ }^{51}$ or result from interactions of the integrins with lipid-derived mediators. ${ }^{1}$ Recently, it has been shown that integrin function is also subject to modulation by interaction with other membrane proteins, including other integrins. ${ }^{52-56}$ The glycosyl-phosphatidylinositol (GPI)-linked cell surface protein urokinase receptor (UPAR), which can function as an adhesion receptor for vitronectin with distinct sites for binding both vitronectin and urokinase, ${ }^{52,53}$ can interact with the active form of $\beta_{1}$-containing integrins to form a stable integrin-uPARcaveolin complex that suppresses the cells' normal $\beta_{1}$ dependent adhesion to fibronectin. The result is that UPAR alters cells' ability to adhere and interact with different extracellular matrices (and/or different environmental signals) via the interactions it establishes through its integrin-uPAR-caveolin connection with the cytoskeleton. ${ }^{52,53}$ Other studies have identified transmembrane adaptors such as the integrin-associated protein (IAP), which is physically and functionally associated with the $\alpha_{\mathrm{v}} \beta_{3}$ and $\alpha_{\mathrm{llb}} \beta_{3}$ integrins. ${ }^{57}$ IAP not only cooperates with $\beta_{3}$ integrins in binding to thrombospondin, but also appears to activate a heterotrimeric Gi protein-dependent intracellular pathway leading to activation of tyrosine kinase Syk and its association with FAK. As such, IAP seems to work in concert with $\beta_{3}$ integrins to regulate intracellular signaling in response to thrombospondin. 27,57

It is now clear that altered, modulated, or regulated integrin interactions can change the way cells interact with their environment with dramatic and far-reaching consequences for both normal and pathological conditions. This is apparent from studies that have shown that perturbation of certain integrins, either by ligation or by treatment with certain anti-integrin antibodies, can result in the generation of signals that cause an increase in intracellular $\mathrm{pH}^{26,58,59}$ and $\mathrm{Ca}^{2+}$ levels, ${ }^{26,60}$ changes in inositol lipid synthesis, ${ }^{26,61}$ tyrosine phosphorylation of pp125 $5^{\mathrm{FAK}},{ }^{11,12,26}$ and activation of p34/cdc $2^{13,26}$ cyclin $A,{ }^{26,62}$ protein kinase $C,{ }^{26,63}$ mitogen-activated protein kinase (MAPK), ${ }^{15,26}$ phosphatidylinositol 3-kinase, ${ }^{17,18,26}$ p21 Ras, ${ }^{20,26}$ and NF- $\kappa$ B. ${ }^{20,21,26,64}$ Furthermore, recent studies have shown that the $\alpha_{v} \beta_{3}$ integrin on melanoma cells can bind and localize proteolytically active MMP-2 on the cell surface, facilitating cell-mediated collagen degradation and directed cellular invasion. ${ }^{65}$ Integrins have also been shown to act synergistically with growth 
factor receptors to modulate cellular functions including cell growth ${ }^{66}$ and migration. ${ }^{67}$

One of the most diversely functional integrins studied to date is the $\alpha_{v} \beta_{3}$ integrin. This integrin is the original, classic vitronectin receptor which recognizes the RGD binding motif found in vitronectin. ${ }^{1,2,3}$ The $\alpha_{v}$ subunit is now known to associate with at least five out of the eight different $\beta$ subunits, making it one of the most promiscuous subunits studied so far. When associated with the $\beta_{3}$ subunit, the $\alpha_{\mathrm{v}} \beta_{3}$ integrin can bind to vitronectin and colocalize to focal adhesion sites with the proteins vinculin, talin, and $\alpha$-actinin at the end of actin filaments. When associated with the $\beta_{5}$ subunit, this homologous integrin can bind vitronectin but remains randomly distributed over the surface of the cells and does not localize to focal adhesion sites. ${ }^{68}$ Recent work has shown that the cytoplasmic tail of the $\beta_{3}$ chain undergoes tyrosine phosphorylation upon adhesion of the $\alpha_{\mathrm{v}} \beta_{3}$ integrin to vitronectin, antibody perturbation of the integrin, or incubation with a manganese-containing buffer. This phosphorylation, which requires the presence of the cytoplasmic tail of the $\alpha_{v}$ subunit, does not occur in the $\beta_{5}$ subunit of the $\alpha_{v} \beta_{5}$ integrin under similar conditions. ${ }^{51}$

The ability of the $\alpha_{\mathrm{v}} \beta_{3}$ integrin to cluster on the cell surface and colocalize with cytoskeletal elements in response to specific stimuli can result in polymerization of the actin cytoskeleton and lead to changes in cell morphology and migratory ability. This permits the integrin to act as a physical bridge between external stimuli and the cells' cytoskeleton, and as a transducer of messages from outside the cell to its internal signal processing pathways. Ultimately, changes in adhesiveness of cells for their environment, through integrins like the $\alpha_{\mathrm{v}} \beta_{3}$ integrin, can lead to gross changes in cellular morphology via the actin cytoskeleton, which is directly involved in cell migration. In this respect, high expression of the $\alpha_{\mathrm{v}} \beta_{3}$ integrin has been associated with different motile cells in vivo including neural crest cells, vascular endothelial cells, and malignant melanoma cells. ${ }^{1,2,26}$ Recent work has identified the NPXY motif within the $\beta_{3}$ subunit (comprising residues 744-747) as essential for cell morphological and migratory responses (cell attachment, spreading, and migration on a immobilized ligand) mediated by the $\alpha_{\mathrm{v}} \beta_{3}$ integrin both in vitro and in vivo. ${ }^{69}$ This work showed that the hamster cell line CS-1 could be transfected with and express the wild-type $\alpha_{\mathrm{v}} \beta_{3}$ integrin, leading to a change in the cells' migratory response to vitronectin and the acquisition of an ability to form spontaneous pulmonary metastases in a chick embryo grown on a chorioallantoic membrane. Mutations in the NPXY region of transfected $\alpha_{\mathrm{v}} \beta_{3}$ integrin abrogated the cells' metastatic ability and migratory response to vitronectin but did not disrupt the integrin's ability to bind to vitronectin. ${ }^{69}$ Other work has shown that ligation of different integrins, including $\alpha_{\mathrm{v}} \beta_{3}$ on human melanoma cells, can lead to altered protein expression associated with increased invasive ability in vitro. ${ }^{70}$ More specifically, as an extension of the work by Werb and colleagues ${ }^{71}$ that demonstrated that the $\alpha_{5} \beta_{1}$ integrin could transduce extracellular signals in rabbit synovial fibroblasts resulting in a change in the cells' expression and extracellular levels of collagenase and stromelysin, work with the human melanoma cell line A375M showed that ligation of the $\alpha_{v} \beta_{3}$ integrin with vitronectin (either matrix bound or soluble) or an activating antibody to the $\alpha_{\mathrm{v}}$ subunit could increase the expression and extracellular levels of the matrix-metalloproteinase-2 enzyme (MMP-2, gelatinase A) coincident with an increase in the cells' ability to invade in vitro. ${ }^{70}$ As a whole, these results suggest a role for the $\alpha_{v} \beta_{3}$ integrin in the pathological progression of melanoma that is facilitated by specific $\alpha_{\mathrm{v}} \beta_{3}$ integrinmediated interactions of cells with their extracellular environment. These interactions can then generate physical (possibly mechanical) ${ }^{72-74}$ and biochemical signaling events that contribute to a change in cell behavior resulting in an aggressive, pathological phenotype.

Significant in light of these observations is the evidence presented by Hsu and colleagues in this issue ${ }^{75}$ that the $\alpha_{\mathrm{v}} \beta_{3}$ integrin plays a direct role in the progression of human primary cutaneous melanoma from the nontumorigenic, nonmetastatic radial growth phase to the tumorigenic, metastatically competent vertical growth phase. An important aspect of this work was the approach that Hsu and colleagues used to design and perform these studies. First, information about the longterm clinical and histopathological observations of cutaneous melanoma formed the basis for defining the disease and its progression in patients and provided the touchstone for the results obtained in the laboratory. Second, using these in vivo observations, Hsu and colleagues isolated and propagated in vitro cells derived from different stages of the disease as a model for primary cutaneous melanoma progression as defined in vivo. Care was taken to correlate the biological properties of the different isolated cell types in culture with observed biological properties and stages in vivo. Significant in the planning and execution of these experiments was the authors' progression from the reductionist in vitro cell culture model of the disease stages to the more complex three-dimensional skin reconstruct model which recreates the physiological milieu of the in vivo environment. Unlike other traditional invasion assays, this model accounts for both tumor cell-derived mechanisms and microenvironmental factors from stromal cells during the invasive process. Therefore, differences between the control and $\beta_{3}$ transfected cells could be observed and the invasion by transfected melanoma cells deep into the dermis without entering apoptosis could be clearly delineated from the control cells, which did not invade but remained in the epidermis and entered apoptosis. Ultimately, the experiments returned to the in vivo SCID mouse model where tumorigenicity of early stage melanoma cells was shown to increase after forced expression of the $\beta_{3}$ subunit.

Central to this experimental approach was the clinical observation that the onset of expression of the $\beta_{3}$ integrin was one of the most specific markers for identifying the transition of primary human cutaneous melanoma from the nontumorigenic, nonmetastatic radial growth phase to the tumorigenic, metastatically competent vertical growth phase. Hsu et al demonstrated that forced expression of the $\beta_{3}$ integrin subunit (via adenovirus gene 
transfer) results in the expression of a functional $\alpha_{\mathrm{v}} \beta_{3}$ integrin and in a malignant phenotype that corresponds to the observed in vivo progression of cells from radial growth phase to vertical growth phase. This study not only contributes to the growing body of work that clearly identifies the importance of integrin analysis in the diagnosis and prognostic evaluation of diseases, but also is the first to extend clinical observations about a key prognostic marker for cutaneous melanoma progression to the demonstration of a specific functional role for the $\beta_{3}$-containing integrin $\alpha_{v} \beta_{3}$ in vitro and in vivo, which directly correlates with the progression of the disease as clinically defined. In conclusion, these results clearly provide the rational basis for research that is just now beginning to identify integrins as unique biological targets for tumor therapy, ${ }^{34,76}$ as potential targets for inhibiting or blocking the metastatic cascade, ${ }^{77}$ and as useful tools for targeted chemotherapy strategies in the treatment of cancer based on the selective expression of integrin receptors in the tumor vasculature. ${ }^{78}$

\section{Acknowledgments}

I thank Elisabeth Seftor and Dr. Mary Hendrix for critically reading this manuscript and providing comments to me during its preparation.

\section{References}

1. Hynes RO: Integrins: versatility, modulation, and signaling in cell adhesion. Cell 1992, 69:11-25

2. Gille J, Swerlick RA: Integrins: role in cell adhesion and communication. Ann New York Acad Sci 1996, 797:93-107

3. Ruoslahti E, Pierschbacher MD: New perspectives in cell adhesion: RGD and integrins. Science 1987, 238:491-497

4. Loftus JC, Smith JW, Ginsberg MH: Integrin-mediated cell adhesion: the extracellular face. J Biol Chem 1994, 25235-25238

5. Hynes RO: Integrins: a family of cell surface receptors. Cell 1987, 48:459-552

6. Fornaro M, Languino LR: Alternatively spliced variants: a new view of the integrin cytoplasmic domain. Matrix Biol 1997, 16:185-193

7. Humphries MJ: Integrin activation: the link between ligand binding and signal transduction. Curr Opin Cell Biol 1996, 632-640

8. Gailit J, Ruoslahti E: Regulation of the fibronectin receptor affinity by divalent cations. J Biol Chem 1988, 263:12927-12933

9. Kirchhofer D, Gailit J, Ruoslahti E, Grzesiak J, Pierschbacher MD: Cation-dependent changes in the binding specificity of the platelet receptor GPIIb/IIla. J Biol Chem 1990, 265:18525-18530

10. Schwartz MA, Schaller MD, Ginsberg MH: Integrins: emerging paradigms of signal transduction. Annu Rev Cell Dev Biol 1995, 11:549_ 599

11. Kornberg LJ, Earp HS, Turner CE, Prockop C, Juliano RL: Signal transduction by integrins: increased protein tyrosine phosphorylation caused by clustering of $\beta_{1}$ integrins. Proc Natl Acad Sci USA 1991, 88:8392-8395

12. Guan JL, Shalloway D: Regulation of focal adhesion-associated protein tyrosine kinase by both cellular adhesion and oncogenic transformation. Nature 1992, 358:690-692

13. Symington BE: Fibronectin receptor modulates cyclin dependent kinase activity. J Biol Chem 1993, 267:25744-25747

14. Vuori K, Ruoslahti E: Activation of protein kinase $C$ precedes $\alpha_{5} \beta_{1}$ integrin-mediated cell spreading on fibronectin. J Cell Biol 1993, 268:21495-21462

15. Morino N, Mimura T, Hamasaki K, Tobe K, Ueki K, Kikuchi K, Takehara K, Kadowaki T, Yazaki Y, Nojima Y: Matrix/integrin interaction activates the mitogen-activated protein kinases, p44erk-1, and p42erk-2: J Biol Chem 1995, 270:269-273

16. Schlaepfer DD, Hanks SK, Hunter T: Van der Geer P: Integrin mediated signal transduction linked to Ras pathway by Grb2 binding to focal adhsion kinase. Nature 1994, 372:786-790

17. Chen Q, Kinch MS, Lin TH, Nurridge K, Juliano RL: Integrin mediated cell adhesion activates mitogen activated protein kinases. J Biol Chem 1994, 269:26602-26605

18. Chen H-C, Guan J-L: Association of focal adhesion kinase with its potential substrate phosphatidylinositol 3 kinase. Proc Natl Acad Sci USA 1994, 91:10148-10152

19. Guinebault C, Payrastre B, Racaud-Sultan C, Mazarguil H, Breton M, Maunco G, Plantavid M, Chap H: Integrin-dependent translocation of phosphinositide 3-kinase to the cytoskeleton of thrombin-activated platelets involves specific interaction of p85a with actin filaments and focal adhesion kinase. J Cell Biol 1995, 129:831-842

20. Kapron-Bras C, Fitz-Gibbon L, Jeevaratnam P, Wilkins J, Dedhar S: Integrin clustering stimulates p21ras activation. J Biol Chem 1993, 268:20701-20704

21. Yebra M, Filardo E, Bayna E, Kawahara J, Cheresh D: Induction of carcinoma cell migration on vitronectin by NF- $\kappa$ B dependent gene expression. Mol Biol Cell 1995, 6:841-850

22. Scatena M, Almeida M, Chaisson ML, Fausto N, Nicosia RF, Giachelli $\mathrm{CM}$ : NF $\kappa \mathrm{B}$ mediates $\alpha \mathrm{v} \beta 3$ integrin-induced endothelial cell survival: J Cell Biol 1998, 141:1083-1093

23. Yamada KM, Miyamoto S: Integrin transmembrane signaling and cytoskeletal control. Curr Opin Cell Biol 1995, 7:681-689

24. Parsons JT: Integrin-mediated signalling: regulation by protein tyrosine kinases and small GTP-binding proteins. Curr Opin Cell Biol 1996, 8:146-152

25. Lafrenie RM, Yamada KM: Integrins and matrix molecules in salivary gland cell adhesion, signaling, and gene expression. Ann New York Acad Sci 1998, 842:42-48

26. Varner AJ, Cheresh DA: Integrins and cancer. Curr Opin Cell Biol 1996, 8:724-730

27. Giancotti FG: Integrin signaling: specificity and control of cell survival and cell cycle progression. Curr Opin Cell Biol 1997, 9:691-700

28. Rosmarin AG, Luo M, Caprio DG, Shang J, Simkevich CP: Sp1 cooperates with the ets transcription factor, GABP, to activate the CD18 ( $\beta 2$ leukocyte integrin) promotor: J Biol Chem 1998, 273: 13097-13103

29. Thomas GJ, Jones J, Speight PM: Integrins and oral cancer. Oral Oncology 1997, 33:381-388

30. Ruoslahti E, Reed J: Anchorage independence, integrins and apoptosis. Cell 1994, 77:477-478

31. Meredith JE Jr, Schwartz M: Integrins, adhesion, and apoptosis: Trends Cell Biol 1997, 7:146-150

32. Frisch SM, Ruoslahti E: Integrins and anoikis. Curr Opin Cell Biol 1997, 9:701-706

33. Brooks PC, Montgomery MP, Rosenfeld, M, Reisfeld RA, Hu T, Klier $\mathrm{G}$, Cheresh DA: Integrin $\alpha \vee \beta 3$ antagonists promote tumor regression by inducing apoptosis of angiogenic blood vessels. Cell 1994, 79: 1157-1164

34. Joseph-Silverstein J, Silverstein RL: Cell adhesion molecules: an overview. Cancer Invest 1998, 16:176-182

35. Holzmann B, Gosslar U, Bittner M: $\alpha_{4}$ integrins and tumor metastasis. Curr Topics Microbiol Immunol 1998, 231:125-141

36. Nip J, Brodt $\mathrm{P}$ : The role of the integrin vitronectin receptor, $\alpha_{v} \beta_{3}$ in melanoma metastasis. Cancer Metastas Rev 1995, 14:241-252

37. Akiyama SK, Olden K, Yamada KM: Fibronectin and integrins in invasion and metastasis. Cancer Metastas Rev 1995, 14:173-189

38. Li X, Graner MW, Williams EL, Roote CE, Bunch TA, Zusman S: Requirements for the cytoplasmic domain of the alphaPS1, alphaPS2 and betaPS integrin subunits during Drosophila development. Development 1998, 125:701-711

39. Van der Flier A, Gaspar AC, Thorsteinsdottir S., Baudoin C, Groeneveld E, Mummery CL, Sonnenberg A: Spacial and temporal expression of the $\beta 1 \mathrm{D}$ integrin during mouse development. Dev Dyn 1997 , 210:472-486

40. Sueoka K, Shiokawa S, Miyazaki T, Kuji N, Tanaka M, Yoshimura Y Integrins and reproductive physiology: expression and modulation in fertilization, embryogenesis, and implantation. Fertil Steril 1997, 67: $799-811$ 
41. Faull RJ, Ginsberg MH: Inside-out signaling through integrins. J Am Soc Nephrol 1996, 7:1091-1097

42. Van Waes C: Cell adhesion and regulatory molecules involved in tumor formation, hemostasis, and wound healing. Head Neck 1995, 17:140-147

43. Brooks PC, Clark RAF, Cheresh DA: Requirement of vascular integrin $\alpha_{\vee} \beta_{3}$ for angiogenesis. Science 1994, 264:569-571

44. Sepp NT, Li L-J, Lee KH, Brown EJ, Caughman SWW, Lawley TJ, Swerlick RA: Basic fibroblast growth factor increases expression of the $\alpha_{v} \beta_{3}$ complex on human microvessel endothelial cells. J Invest Dermatol 1994, 103:295-299

45. Enenstein J, Waleh NS, Kramer RH: Basic FGF, and TGF $\beta$ differentially modulate integrin expression of human microvascular endothelial cells: Exp Cell Res 1992, 203:499-503

46. Friedlander M, Brooks PC, Shaffer RW, Kincaid CM, Varner JA, Cheresh DA: Definition of two angiogenic pathways by distinct $\alpha_{\mathrm{v}}$ integrins. Science 1995, 27:1500-1502

47. Brooks P, Stromblad S, Klemke R, Visscher D, Starkar F, Cheresh D: Antiintegrin $\alpha \vee \beta 3$ blocks breast cancer growth, and angiogenesis in human skin: J Clin Invest 1995, 96:1815-1822

48. Drake CJ, Cheresh DA, Little CD: An antagonist of integrin $\alpha_{v} \beta_{3}$ prevents maturation of blood vessels during embryonic neovascularization. J Cell Sci 1995, 108:2655-2661

49. Gavrilovskaya IN, Shepley M, Shaw R, Ginsberg MH, Mackow ER: Beta(3) integrins mediate the cellular entry of hantaviruses that cause respiratory failure: Proc Natl Acad Sci USA 1998, 95:7074-7079

50. Coburn J, Magoun L, Bodary SC, Leong LM: Integrins $\alpha(\mathrm{v}) \beta(3)$, and apha(5) $\beta(1)$ mediate attachment of lyme disease spirochetes to human cells: Infection Immunity 1998, 1952, 66:1946

51. Blystone SD, Lindberg FP, Williams MP, McHugh KP, Brown EJ: Inducible tyrosine phosphorylation of the $\beta 3$ integrin requires the alphav integrin cytoplasmic tail. J Biol Chem 1996, 271:31458-31462

52. Wei Y, Lukashev M, Simon DI, Bodary SC, Rosenberg S., Doyle MV, Chapman HA: Regulation of integrin function by the urokinase receptor. Science 1996, 273:1551-1555

53. Chapman HA: Plasminogen activators, integrins, and coordinated regulation of cell adhesion and migration. Curr Opin Cell Biol 1997, 9:714-724

54. Schwartz MA: Integrins, oncogenes, and anchorage independence. J Cell Biol 1997, 139:575-578

55. Bauer JS, Schreiner CL, Giancotti FG, Ruoslahti E, Juliano RL: Motility of fibronectin receptor-deficient cells on fibronectin and vitronectin: collaborative interactions among integrins. J Cell Biol 1992, 116:477487

56. Simon, KO, Nutt EM, Abraham DG, Rodan GA, Duong LT: The $\alpha_{v} \beta_{3}$ integrins regulates $\alpha_{5} \beta_{1}$-mediated cell migration toward fibronectin. J Biol Chem 1997, 272:29380-29389

57. Chung J, Gao AF, Frazier WA: Thrombospondin acts via integrinassociated protein to activate the platelet integrin $\alpha_{11 \mathrm{~b}} \beta_{3}$. J Biol Chem 1993, 123:485-496

58. Schwartz MA, Both G, Lechene C: Effect of cell spreading on cytoplasmic $\mathrm{pH}$ in normal and transformed fibroblasts. Proc Natl Acad Sci USA 1989, 86:4525-4529

59. Schwarz MA, Gragoe EJ Jr, Lechene CP: pH regulation in spread and round cells. J Biol Chem 1990, 265:1327-1332

60. Schwartz MA: Spreading of human endothelial cells on fibronectin or vitronectin triggers elevation of intracellular free calcium. J Cell Biol 1992, 120:1003-1010
61. McNamee HP, Ingber, DE, Schwartz MA: Adhesion to fibronectin stimulates inositol lipid synthesis and enhances PDGF-induced inositol lipid breakdown. J Cell Biol 1993, 121:673-678

62. Guadagno TM, Ohtsubo M, Roberts JM, Assoian RK: A link between cyclin A expression and adhesion-dependent cell cycle proliferation. Science 1993, 262:1572-1575

63. Vuori K, Ruoslahti E: Association of insulin receptor substrate-1 with integrins. Science 1994, 226:1576-1578

64. Kheradmand F, Werner E, Tremble P, Symons M, Werb Z: Role of Rac1 and oxygen radicals in collagenase- 1 expression induced by cell shape change. Science 1998, 280:898-902

65. Brooks PC, Stromblad S, Sanders LC, von Schalscha TL, Aimes RT, Stetler-Stevenson WG, Quigley JP, Cheresh: Localization of matrix metalloproteinase MMP-2 to the surface of invasive cells by interactions with integrin $\alpha_{v} \beta_{3}$. Cell 1996, 85:683-693

66. Schneller M, Vuori K, Ruoslahti E: $\alpha \vee \beta 3$ integrin associates with activated insulin, and PDGF $\beta$ receptors, and potentiates the biological activity of PDGF. EMBO J 1997, 16:5600-5607

67. Woodard AS, Garcia-Cardena G, Leong M, Madri JA, Sessa WC, Languino LR: The synergistic activity of $\alpha_{\mathrm{v}} \beta_{3}$ integrin and PDGF receptor increases cell migration. J Cell Science 1998, 111:469-478

68. Wayner EA, Orlando RA, Cheresh DA: Integrins $\alpha_{v} \beta_{3}$ and $\alpha_{v} \beta_{5}$ contribute to cell attachment to vitronectin but differentially distribute on the cell surface: J Cell Biol 1991, 113:919-929

69. Filardo EJ, Brooks PC, Deming SL, Damsky C, Cheresh JA: Requirement of the NPXY motif in the integrin $\beta_{3}$ subunit cytoplasmic tail for melanoma cell migration in vitro and in vivo. J Cell Biol 1995, 130: $441-450$

70. Seftor REB, Seftor EA, Gehlsen KR, Stetler-Stevenson WG, Brown PD, Ruoslahti E, Hendrix MJC: Role of the $\alpha_{v} \beta_{3}$ integrin in human melanoma cell invasion. Proc Natl Acad Sci USA 1992, 89:1557-1561

71. Werb Z, Tremble PM, Behrendtsen O, Crowley E, Damsky CH: Signal tansduction through the fibronectin receptor induces collagenase and stromelysin gene expression. J Cell Biol 1989, 109:877-889

72. Chicurel ME, Singer RH, Meyer CJ, Ingber DE: Integrin binding and mechanical tension induce movement of mRNA and ribosomes to focal adhesions. Nature 1998, 392:730-733

73. Schmidt C, Pommerenke H, Durr, F, Nebe B, Rychly J: Mechanical stressing of integrin receptors induces enhanced tyrosine phosphorylation of cytoskeletally anchored proteins. J Biol Chem 1998, 273: 5081-5085

74. Maniotis AJ, Chen CS, Ingber DE: Demonstration of mechanical connections between integrins, cytoskeletal filaments, and nucleoplasm that stabilize nuclear structure. Proc Natl Acad Sci USA 1997, 94:849-854

75. Hsu M-Y, Shi D-T, Meier FE, Van Belle P, Hsu J-Y, Elder DE, Buck CA, Herlyn M: Adenoviral gene transfer of $\beta_{3}$ integrin subunit induces conversion from radial to vertical growth phase in primary human melanoma. Am J Pathol 1998, 1435-1442

76. Ruoslahti E: Integrins as signaling molecules and targets for tumor therapy. Kidney International 1997, 51:1413-1417

77. Yun Z, Menter DG, Nicolson GL: Involvement of the integrin $\alpha(v) \beta 3$ in cell adhesion, motility, and liver metastasis of murine RAW117 large cell lymphoma. Cancer Res 1996, 56:3103-3111

78. Arap W, Pasqualini R, Ruoslahti E: Cancer treatment by targeted drug delivery to tumor vasculature in a mouse model. Science 1998, 279: $377-380$ 